\title{
Slim Water Injection Nozzle for Silicon Wafer Wet Cleaning Bath
}

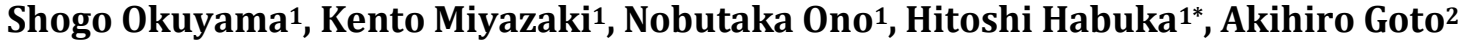 \\ ${ }^{1}$ Department of Chemical and Energy Engineering, Yokohama National University, Yokohama, Japan \\ ${ }^{2}$ Shizuoka Factory, Pre-Tech Co., Ltd., Yaizu, Japan \\ Email: ^habuka-hitoshi-ng@ynu.ac.jp
}

How to cite this paper: Okuyama, S., Miyazaki, K., Ono, N., Habuka, H. and Goto, A. (2016) Slim Water Injection Nozzle for Silicon Wafer Wet Cleaning Bath. Advances in Chemical Engineering and Science, 6, 345354.

http://dx.doi.org/10.4236/aces.2016.64035

Received: August 22, 2016

Accepted: September 9, 2016

Published: September 12, 2016

Copyright $\odot 2016$ by authors and Scientific Research Publishing Inc. This work is licensed under the Creative Commons Attribution International License (CC BY 4.0).

http://creativecommons.org/licenses/by/4.0/

\begin{abstract}
In order to effectively and quickly clean the surface of semiconductor silicon wafers, the fluid flow is one of the significant issues. For a batch-type silicon wafer wet cleaning bath, a slim water injection nozzle consisting of a dual tube was studied, based on theoretical calculations and experiments. A thin inner tube was placed at the optimum position in the water injection nozzle. Such a simple design could make the water injection direction normal and the water velocity profile symmetrical along the nozzle. The water flow in the wet cleaning bath was observed using a bluecolored ink tracer. When the nozzle developed in this study was placed at the bottom of the bath, a fast and symmetrical upward water stream was formed between and around the wafers.
\end{abstract}

\section{Keywords}

Silicon Wafer, Wet Cleaning Bath, Water Injection Nozzle, Water Flow

\section{Introduction}

Semiconductor electronic devices are fabricated from semiconductor materials by various thermal, chemical and mechanical processes [1] [2]. In order to maintain the material's surface clean, wet cleaning is one of the most popular techniques. For the semiconductor silicon wafer production, the batch-type wafer cleaning bath [3]-[18] is very often used for economic reasons. In order to further reduce the time and cost of the wafer cleaning, its physics, chemistry and engineering should be studied and optimized in detail. It should be noted that the water flow in the cleaning bath [16]-[18] is still one of the most important engineering issues.

The wafer cleaning process uses various chemicals and ultrapure water, often with 
ultrasonic waves. Water and chemicals are injected from the nozzle located in the bath. The liquid should sufficiently go through the spaces between the arranged wafers in order to detach and remove the particles and impurities from the wafer surfaces. However, cross contamination [18] often occurs due to the recirculation that exists in the bath. Sato et al. [18] thus studied various ways of chemical supply, such as changing the total chemical supply amount and its interval, through the wafers having various spaces between them. For achieving an effective and quick cleaning process, by enhancing the conclusions of notable existing studies, any issues relating to the bath should be carefully designed. Because any contaminations should be smoothly removed from the bath, a one-way water flow without recirculation should be achieved in the bath.

The one-way water flow is expected to be formed by the water injection from the nozzle into the bath. The water injection direction and its velocity profile initiate and govern the water flow patterns. If the water direction from the nozzle was even very slightly slanted in one direction, a huge recirculation can occur in the bath, such as the flow around the wafer array. Thus, the nozzle should be carefully designed taking into account the following issues:

1) The water injection direction is normal to the nozzle body [17] [18].

2) The water velocity profile is symmetrical and uniform, as much as possible, along the nozzle.

3) The nozzle body is as small as possible.

and

4) The fabrication is easy with a reasonable cost.

For items 1) and 2), the water injection direction has been evaluated in our previous studies [16] [17] for a bath which cleaned 25 pieces of the 300-mm-diameter silicon wafers. Although the thicker wall of the nozzle was found to better generate a normal water injection, the water direction depends on the water flow velocity in the nozzle. 3 ) is for the frequent use of ultrasonic waves, often irradiated from the bottom of the bath. The materials present between the ultrasonic resonators and the wafers should be reduced or minimized so that the ultrasonic wave sufficiently reaches the wafer surface [1] [2] [16]. Thus, the shape of the water injection nozzle should be very slim. Additionally, the design should be simple for easy and low cost fabrication.

In this study, the water injection nozzle was thus designed and verified, based on theoretical calculations and the water flow visualization. First, the nozzle was improved by adding small parts, that is, an inner tube. Next, the entire water flow in the bath was observed for verifying the design concept.

\section{Experimental Procedures}

The parameters in this study were chosen for reproducing the actually-used industrial conditions, particularly accounting for those of the wet cleaning after the silicon wafer surface grinding. Figure 1 shows the batch-type silicon wafer wet cleaning bath containing two water injection nozzles and six 300-mm-diameter silicon wafers. Figure 1(a) and Figure 1 (b) are the front view and the right side view, respectively. The six 


\section{$\begin{array}{ll}\text { (a) Front } \quad \text { (b) Right side } & \end{array}$}

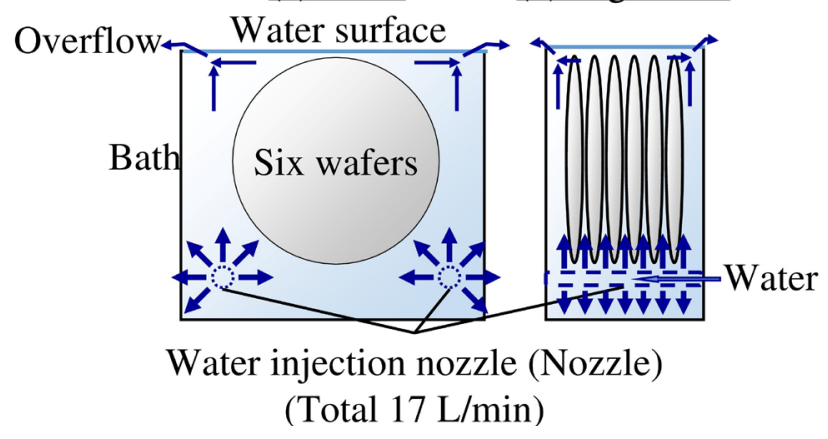

Figure 1. Batch-type silicon wafer wet cleaning bath. (a) Front view and (b) right side view. The bath contains six 300-mmdiameter wafers and two water injection nozzles (Nozzle). Water is injected into the bath from the nozzle. Water finally overflows via the top wall of the bath.

wafers were supported by a cassette, not shown in this figure, and were placed at the center bottom of the bath. The cleaning bath shown in Figure 1 was customized for only six wafers, because this is mainly used for the wafers, the surface of which had a significant amount of mud-like waste immediately after the surface grinding. In this study, 300-mm-diameter transparent glass wafers were used instead of silicon wafers for observing the motions of the tracer described below.

The water was introduced from the two water injection nozzle set at the right and left bottom of the bath. The water flow direction through the inner water injection nozzle was from right to left in Figure 1(b).

The water injection nozzle had eleven pinholes per one array. The diameter of each pinhole was $1.5 \mathrm{~mm}$. The distance between the pinholes was $10 \mathrm{~mm}$. The nozzle had six pinhole arrays, as indicated by the arrows in Figure 1(b). The water oriented to the wall was expected to prevent formation of a stagnant region, easily formed at the bottom side edge of the bath. The total water flow rate was $17 \mathrm{~L} \cdot \mathrm{min}^{-1}$; each nozzle supplied water at $8.5 \mathrm{~L} \cdot \mathrm{min}^{-1}$. The water supplied from the nozzle flowed to the water surface via the spaces between the wafers and the spaces around the wafer array. Finally, the water overflowed from the top wall of the bath. This bath had the function of ultrasonic wave irradiation from the entire bottom of the bath without any disturbance, because the nozzle satisfied item 3) in Introduction. For effectively utilizing the ultrasonic wave, this type of bath is considered to be better than the baffle type bath [19].

Figure 2 shows the ordinary water injection nozzle, labeled Type-A. The outside and inside diameters were 19 and $15 \mathrm{~mm}$, respectively. The right side was open, while the left side was closed. The pinholes were linearly arranged along the nozzle wall. The diameter of the pinholes was $1.5 \mathrm{~mm}$. One pinhole array had eleven pinholes, from \#1 to \#11. There were six pinhole arrays, a, b, c, d, e and f, as shown in Figure 2(a).

Figure 3 is a schematic of the Type-B nozzle, which has both outer and inner tubes. The outer tube was exactly the same as that indicated as the "Nozzle" shown in Figure 2. The right and left ends of the outer tube were open and closed, respectively. The eleven 


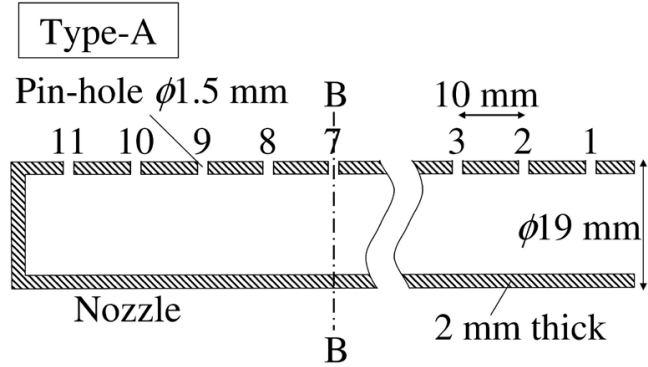

(a) A-A

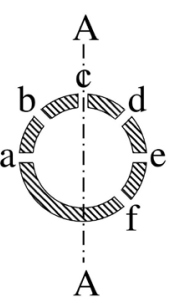

(b) B-B

Figure 2. Schematic of Type-A nozzle, consisting of a 19-mmdiameter tube, the left end of which is closed. Each of the six arrays, a, b, c, d, e, and f, has eleven straight holes. (a) A-A cross section of (b), and (b) B-B cross section of (a).

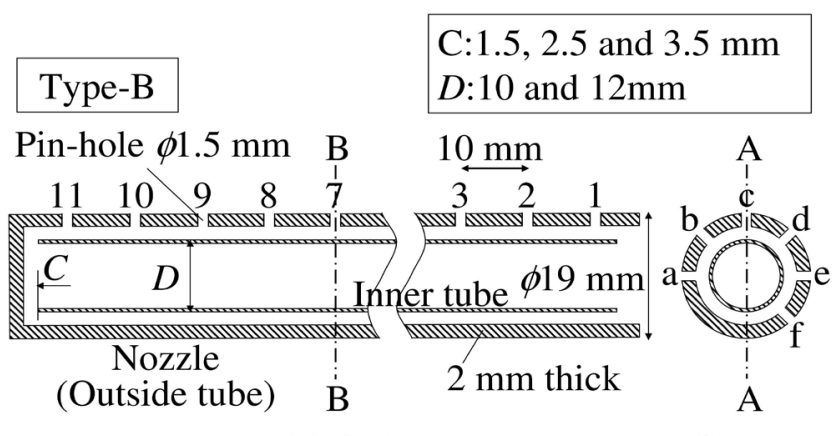

(a) A-A

(b) B-B

Figure 3. Schematic of Type-B nozzle, consisting of a 19-mmdiameter outer tube, and 10 and $12-\mathrm{mm}$-diameter inner tube. Each of the six lines, $a, b, c, d, e$, and $f$, has eleven straight holes.

(a) A-A cross section of (b), and (b) B-B cross section of (a).

pinholes having 1.5-mm-diameters were linearly arranged per one array; there were six arrays, indicted as a, b, c, d, e, and f. The inner tube was a simple tube, both ends of which were open. The clearance at the left end, C, was adjusted between 1.5 and 3.5 $\mathrm{mm}$.

The directions of the water injected using the Type-A and B nozzles in the bath were visualized using a tracer, such as the blue-colored ink, and were captured by a VTR camera.

\section{Numerical Calculations}

The water motions produced by the Type-A and B nozzles were analyzed using numerical calculations taking into account the conservation of mass and momentum. The schematic of the Type-A and B nozzles was discretized using Fluent software (ANSYS Inc., USA) for calculating the water flow from the entrance of the nozzle to the pinholes as the outlet. The water flow rate was $8.5 \mathrm{~L} \cdot \mathrm{min}^{-1}$ for one nozzle. At the pinhole, the water was assumed to go out from the nozzle to the open air. In the calculation, the direction and the velocity of the injected water at the pinholes were the focus. Addition- 
ally, the water motions of the inside and outside of the inner tube were optimized by adjusting the $\mathrm{C}$ and $\mathrm{D}$ values shown in Figure 3.

\section{Results and Discussion}

\subsection{Type-A Nozzle}

First, the water injection from the Type-A nozzle was observed as shown in Figure 4. The water coming from the right-side entrance approached the left end, accompanying the water injection from each pinhole, as indicated by the arrows. The blue-colored lines in this figure show the direction of the injected water from the pinholes. Although the water flow direction from right to left in the nozzle was switched to the upper direction, the momentum in the horizontal direction slightly remained. As indicated in Figure 4 , the water was injected upward, but slanted 10 degrees to the left.

\subsection{Type-B Nozzle}

Figure 5 and Figure 6 show the tracer motion observed using the Type-B nozzle versus the time. Figure 5(c) and Figure 6(c) show the tracer motion after beginning of the tracer injection. Overall, the tracer directions shown in these figures are concluded to be normal. The first conclusion was that the normal water injection was successfully obtained by the Type-B nozzle.

Next, the effect of the $C$ value and the mechanism to achieve the normal water injection were evaluated. Figure 5 shows the water injection from the Type-B nozzle observed using the blue-colored ink tracer. The $C$ value was $2.5 \mathrm{~mm}$. Figure $5(\mathrm{e})$ is a schematic of the water path in the Type-B nozzle. The water coming from the right side entrance is divided into two paths, such as Paths I and II. The water following Path II goes through the space between the inner tube and the outside tube. The water following Path I reaches the left end of the nozzle and turns back to enter the space between the inner tube and the outside tube. Thus, the water following Path I approaches the center pinholes of \#4-8 earlier than that following path II to the same pinholes.

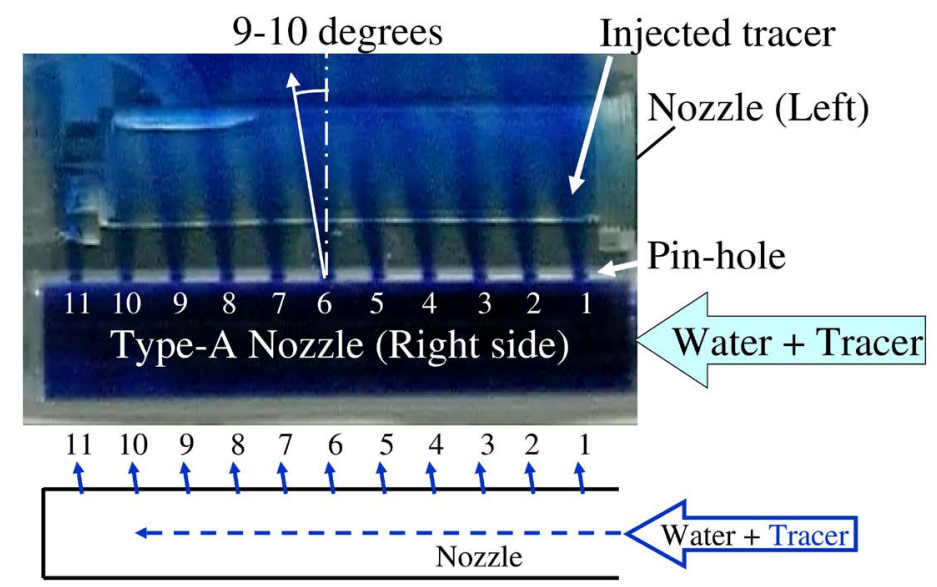

Figure 4. Water injection from Type-A nozzle observed using blue-colored ink tracer. 
(a)

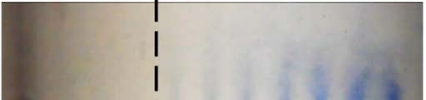

Type-B

$C: 2.5 \mathrm{~mm}$

D: $12 \mathrm{~mm}$

(b)

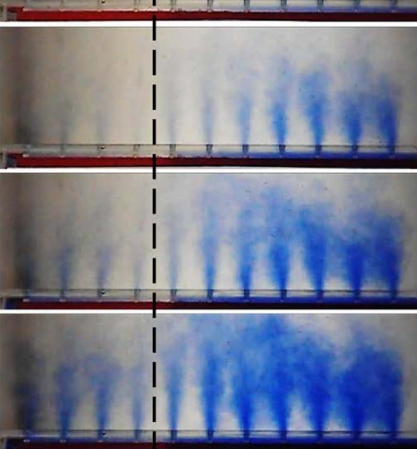

C. $11109817 \quad 65443221$

(e)

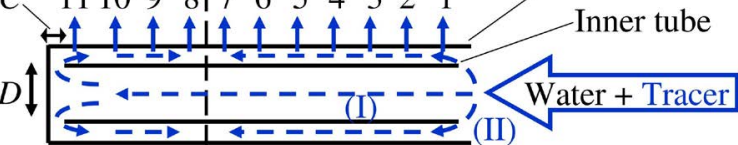

Figure 5. Water injection from Type-B nozzle observed using blue-colored ink tracer. The $\mathrm{C}$ value was $2.5 \mathrm{~mm}$. (a), (b), (c) and (d) are sequential changes in tracer position. (e) Schematic of water path.

(a)

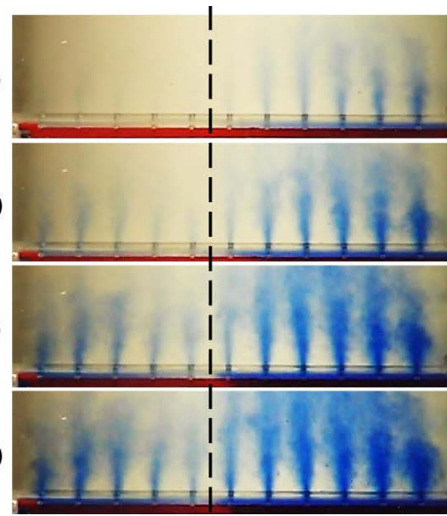

Type-B

C: $3.5 \mathrm{~mm}$

D: $12 \mathrm{~mm}$

(e)

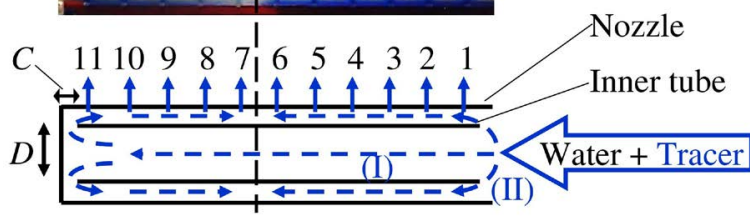

Figure 6. Water injection from Type-B nozzle observed using blue-colored ink tracer. The $\mathrm{C}$ value was $3.5 \mathrm{~mm}$. (a), (b), (c) and (d) are sequential changes in tracer position. (e) Schematic of water path.

Figure 5(a) shows the tracer motion during the early stage. A dense image of the blue-colored ink existed at the pinholes of \#1-3. A very slight blue color could be observed at \#5, \#6 and \#7, while no tracer existed at \#8-11. Figure 5(b) shows the tracer position after the time at Figure 5(a). The blue contrast at the positions between \#1 and \#7 is denser than that in Figure 5(a). Additionally, the blue color at positions \#8-11 
slightly appeared. Next, in Figure 5(c), the blue color contrast was much denser than that in Figure 5(b). The further dense contrast was totally observed in Figure 5(d). Based on the tracer motion, the water motions following Paths I and II are assumed to be distinguished using the dotted line. The high contrast of the blue color came from the right end to the dotted line. Afterwards, the high contrast of the blue color came from the left end to the dotted line. The meeting point coming from Paths I and II is the position indicated using the dotted line, because the blue color contrast was significantly different between positions \#7 and \#8 in Figure 5(c).

In Figure 6, the water motion can be evaluated following the method similar to that in Figure 5. The blue color contrast sequentially intensified, pinhole by pinhole, from both sides of the Type-B nozzle, from Figure 6(a) to Figure 6(d). The water flow following Path I meets with that following Path II at the position between \#6 and \#7. The meeting point in Figure 6 slightly shifted to the center of the Type-B nozzle, rather than that in Figure 5. Thus, the $\mathrm{C}$ value of $3.5 \mathrm{~mm}$ is considered to be better than that of $2.5 \mathrm{~mm}$ from the viewpoint of symmetry.

In order to evaluate the water velocity profile in detail, Figure 7 shows the calculation for the Type-B nozzle. The water velocity was normalized using those in the center region. In Figure 7(a) and Figure 7(b), the $C$ value is $3.5 \mathrm{~mm}$ and $2.5 \mathrm{~mm}$, respectively. The D value of $12 \mathrm{~mm}$ and $10 \mathrm{~mm}$ is indicated using the circle and triangle, respectively.

In Figure 7(a) and Figure 7(b), the water velocities shown using the circles and triangles are overlapped. Thus, the $\mathrm{D}$ value, that is, the inner tube diameter does not cause a significant difference. However, in Figure 7(b), the pinhole giving the maximum velocity by the $\mathrm{D}$ value has a position nearer the center than that by the $10 \mathrm{~mm}$. Thus, the $\mathrm{D}$ value of $12 \mathrm{~mm}$ is expected to produce a symmetrical velocity profile along the Type-B nozzle, even when the $C$ value significantly changes.

Next, the $C$ value, that is, the left end clearance between the inner tube and the outside tube was evaluated. Figure 7 (b) shows that the water velocity at the pinhole position \#11 is significantly lower than those at the other positions. In contrast, the water
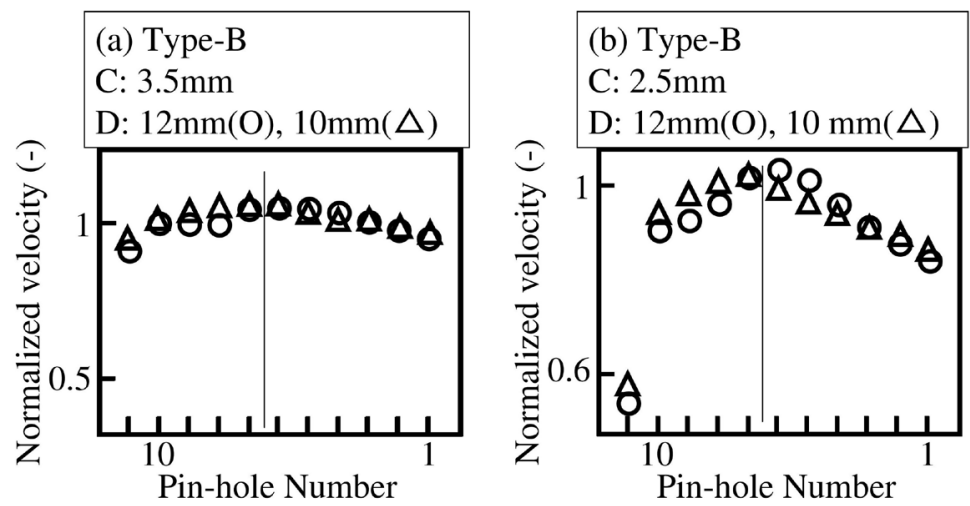

Figure 7. Calculation of normalized water velocity injected from Type-B nozzle. The $C$ value is (a) $3.5 \mathrm{~mm}$ and (b) $2.5 \mathrm{~mm}$. The $\mathrm{D}$ value of $12 \mathrm{~mm}$ and $10 \mathrm{~mm}$ is indicated by circle and triangle, respectively. 
velocity profile in Figure $7(\mathrm{a})$ is flatter than that in Figure $7(\mathrm{~b})$. Thus, the $\mathrm{C}$ value of $3.5 \mathrm{~mm}$ was employed in this study.

\subsection{Water Flow Using Type-B Nozzle}

In addition to the water velocity evaluation at the pinhole, the entire water flow generated by the Type-B nozzle was observed and evaluated in the bath, as shown in Figure 8. In order to evaluate the water velocity profile generated by the nozzle, specifically, concerning the tracer motion between the wafers, the tracer motion observed from the right side was the focus. Because the T-region indicated using the dotted line is the position outside of the bath, used to add the tracer, the blue color in this region was not related to the water flow in the bath. Figures $8(a)-(c)$ show the time sequence of the tracer; while Figure 8 (d) shows a schematic of the water motion. Immediately after the tracer injection, as shown in Figure 8(a), the highest tracer position was the center region where the six wafers were arranged, as shown in Figure 8(d). In Figure 8(b) and Figure $8(\mathrm{c})$, the tracer went up faster in the center region than in the other region. Additionally, the tracer distribution was symmetrical to the center of the bath. Based on the tracer motion shown in Figure 8, the symmetrical water injection profile in the normal direction was recognized to be successfully achieved by the Type-B nozzle.

Because all the entire dimensions of the Type-B nozzle are exactly the same as those of the Type-A, the Type-B nozzle produces no deterioration in the other condition for removing small particles and contaminations including the grinding waste.

\section{Conclusion}

For a silicon wafer wet cleaning bath, a dual-tube-type water injection nozzle was studied, based on theoretical calculations and experiments. A thin inner tube was simply installed and its position was optimized in order to generate a counter flow. Such a simple design could make the water injection direction normal and the water velocity profile symmetrical along the nozzle. The water flow in the wet cleaning bath, observed using blue-colored ink as the tracer, showed the fast upward water stream through the

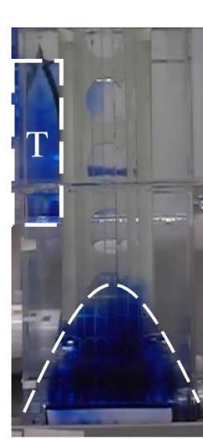

(a)

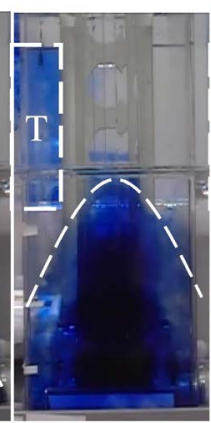

(b)

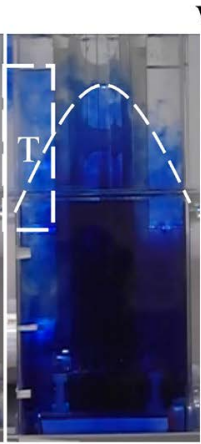

(c)

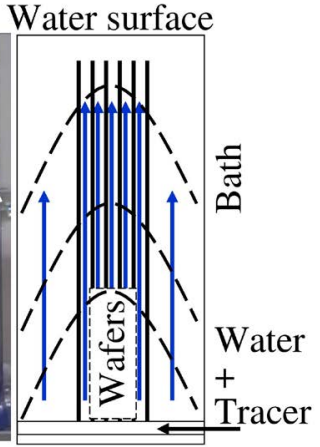

(d)

Figure 8. Observed tracer motion sequentially shown versus time, (a), (b) and (c). (d) is a schematic of the tracer motion. The T-region indicated by the dotted line is where to add the tracer. 
array of six wafers when the nozzle developed in this study was placed at the bottom of the bath. Because the outside dimension of the nozzle caused no change, the water flow was simply improved with no trade-off by this study.

\section{References}

[1] Chang, C.Y. and Sze, S.M. (1996) ULSI Technology. McGraw-Hill, New York.

[2] Shimura, F. (1989) Semiconductor Silicon Crystal Technology. Academic Press, San Diego.

[3] Knotter, D.M., de Gendt, S., Mertens, P.W. and Heyns, M.M. (2000) Silicon Surface Roughening Mechanisms in Ammonia Hydrogen Peroxide Mixtures. Journal of the Electrochemical Society, 147, 736-740. http://dx.doi.org/10.1149/1.1393261

[4] Choia, G.M. and Ohmi, T. (2001) Removal Efficiency of Metallic Impurities on Various Substrates in HF-Based Solutions. Journal of the Electrochemical Society, 148, G241-G248. http://dx.doi.org/10.1149/1.1360189

[5] Gale, G.W., Rath, D.L., Cooper, E.I., Estes, S., Okorn-Schmidt, H.F., Brigante, J., Jagannathan, R., Settembre, G. and Adams, E. (2001) Enhancement of Semiconductor Wafer Cleaning by Chelating Agent Addition. Journal of the Electrochemical Society, 148, G513-G516. http://dx.doi.org/10.1149/1.1391273

[6] Miyashita, N., Uekusa, S. and Katsumata, H. (2002) Characterization of a New Cleaning Method Using Electrolytic Ionized Water for Polysilicon Chemical Mechanical Polishing Process. Japanese Journal of Applied Physics, 41, 5098-5103. http://dx.doi.org/10.1143/JJAP.41.5098

[7] Vos, R., Lux, M., Xu, K., Fyen, W., Kenens, C., Conard, T., Mertens, P., Heyns, M., Hatcher, Z. and Hoffman, M. (2001) Removal of Submicrometer Particles from Silicon Wafer Surfaces Using HF-Based Cleaning Mixtures. Journal of the Electrochemical Society, 148, G683-G691. http://dx.doi.org/10.1149/1.1413483

[8] Chena, Z. and Singh, R.K. (2003) Mechanism of Particle Deposition on Silicon Surface during Dilute HF Cleans. Journal of the Electrochemical Society, 150, G667-G672. http://dx.doi.org/10.1149/1.1610469

[9] Abbadi, A., Crescente, F. and Semeria, M.N. (2004) Advanced Wet Cleanings Post-CMP Application to Reclaim Wafers. Journal of the Electrochemical Society, 151, G57-G66. http://dx.doi.org/10.1149/1.1630809

[10] Ng, D., Huang, P.Y., Jeng, Y.R. and Liang, H. (2007) Nanoparticle Removal Mechanisms during Post-CMP Cleaning. Electrochemical and Solid-State Letters, 10, H227-H231. http://dx.doi.org/10.1149/1.2739817

[11] Claes, M., De Gendt, S., Kenens, C., Conard, T., Bender, H., Storm, W., Bauer, T., Mertens, P. and Heyns, M.M. (2001) Controlled Deposition of Organic Contamination and Removal with Ozone-Based Cleanings. Journal of the Electrochemical Society, 148, G118-G125. http://dx.doi.org/10.4028/www.scientific.net/ssp.76-77.223

[12] Kern, W. (1990) The Evolution of Silicon Wafer Cleaning Technology. Journal of the Electrochemical Society, 137, 1887-1892. http://dx.doi.org/10.1149/1.2086825

[13] Habuka, H., Mizuno, K., Ohashi, S. and Kinoshita, T. (2013) Surface Chemical Reaction Model of Silicon Dioxide Film Etching by Dilute Hydrogen Fluoride Using a Single Wafer Wet Etcher. ECS Journal of Solid State Science and Technology, 2, 264-267. http://dx.doi.org/10.1149/2.013306jss

[14] Habuka, H., Ohashi, S. and Kinoshita, T. (2012) Numerical Calculation Model of a Single Wafer Wet Etcher Using a Swinging Nozzle. Materials Science in Semiconductor Process- 
ing, 15, 543-548. http://dx.doi.org/10.1016/j.mssp.2012.04.005

[15] Habuka, H., Ohashi, S., Tsuchimochi, T. and Kinoshita, T. (2011) Water Motion over a Wafer Surface Rotating in a Single-Water Wet Cleaner. Journal of the Electrochemical Society, 158, H487-H490. http://dx.doi.org/10.1149/1.3630855

[16] Habuka, H., Fukumoto, R., Okada, Y. and Kato, M. (2010) Dominant Forces for Driving Bubbles in a Silicon Wafer Wet Cleaning Bath Using Megasonic Wave. Journal of the Electrochemical Society, 157, H585-H588. http://dx.doi.org/10.1149/1.3365114

[17] Habuka, H., Kobayashi, S., Kato, M., Takeuchi, T. and Aihara, M. (2004) Water Motion in Carrierless Wet Station. Journal of the Electrochemical Society, 151, G814-G818. http://dx.doi.org/10.1149/1.1809580

[18] Sato, N., Yamazaki, O. and Shimogaki, Y. (2012) Impacts of Chemical Supply Flow on Particle Removability in Wet Clean Bath. Journal of the Electrochemical Society, 159, H367H372. http://dx.doi.org/10.1149/2.012204jes

[19] United States Patent \#5885360.

Submit or recommend next manuscript to SCIRP and we will provide best service for you:

Accepting pre-submission inquiries through Email, Facebook, LinkedIn, Twitter, etc. A wide selection of journals (inclusive of 9 subjects, more than 200 journals)

Providing 24-hour high-quality service

User-friendly online submission system

Fair and swift peer-review system

Efficient typesetting and proofreading procedure

Display of the result of downloads and visits, as well as the number of cited articles Maximum dissemination of your research work

Submit your manuscript at: http://papersubmission.scirp.org/ 